\title{
From Speeches to Action: Implementing What is Agreed
}

\section{Richard Jolly}

\section{The Change in Words}

Over the last two years, a remarkable shift has occurred in public international statements about the objectives of adjustment policy in developing countries. Following Secretary of the Treasury James Baker's statement in October 1985, the need for a more growth oriented process of adjustment has become the new orthodoxy, repeated with variations on numerous official occasions ever since. In parallel, awareness had been growing of the human costs of many adjustment programmes. Over 1986/87, the need to protect the poor in the course of adjustment became widely acknowledged internationally, with most of the heads of international agencies making clear declarations of the desirability of more action along these lines.

The World Bank itself presented a paper on this theme, 'Protecting the poor in the course of adjustment', to the Development Committee in April 1987. More recently M. M. Camdessus, the new Managing Director of the IMF, made protection of the vulnerable in the course of adjustment a clear part of his first speech to ECOSOC in June 1987, considerably expanding on the points made by his predecessor $M$. de Larosière one year earlier. That speech marked the first time a Managing Director of the IMF had spoken out on the desirability of adjustment policy paying explicit attention to issues of income distribution, health, nutrition and poverty, M. de Larosiére thus gave the imprimatur of his position as the guardian of financial orthodoxy to the fact that adjustment policies which take account of these human-social factors will be better adjustment policies than those which do not, a position $\mathrm{Mr}$ Camdessus has endorsed and extended.

The annexed quotations show the evolution of these statements of recognition and intent - recognition of the mounting poverty and malnutrition in many countries and public declarations of intent to do something about it. In addition, mention should be made of the many passionate declarations by Third World Heads of State at the 40th Anniversary General Assembly of the United Nations, when a wave of concern with the human consequences of debt on poverty and the consequences for preserving democracy became a major theme of the $40 \mathrm{th}$ anniversary session.

The quotation from the Sub-Committee on Nutrition (SCN) of the ACC (Inter-agency Coordinating Committee of the UN) is significant because the $\mathrm{ACC} / \mathrm{SCN}$ brings toget her in a professional committee all the main UN agencies concerned with nutrition [FAO, UNICEF, WHO, WFP, IFAD, the World Bank, etc.], the donor agencies, Third World representatives and a number of leading academics in the field of nutrition. This body's statement on the rising problem of malnutrition and its links with adjustment policy followed a two-day session on nutrition and adjustment in which the IMF joined. ${ }^{1}$

This meeting was followed one year later by an $\mathrm{ACC} / \mathrm{SCN}$ decision to support a major UNICEF/WHO/FAO initiative to strengthen national efforts for nutrition surveillance, including the rapid processing and release of nutritional data every quarter, so as to make possible the use of nutrition data to guide adjustment policies.

\section{And the Lag in Action}

In spite of these bold statements, action still lags far behind. It was still possible, as recently as November 1986 , for it to be made a condition of international agreement that the price of breakfast meal (a form of maize meal comprising half the marketed maize meal consumed throughout Zambia) be increased by 125 per cent overnight and that this be publicly announced, lest there be any government backsliding after the visiting mission had departed. One has merely to note that maize meal is the main staple food of the country and comprises about half of all processed maize meal purchased by consumers, to realise the impact that this more than doubling of its price had on consumers, especially in a country where two fifths of the population live in the urban areas and therefore have to buy most of their food. Within five days of this announcement, food riots had broken out in the copperbelt and 17 persons were killed. Two days after this, President Kaunda rescinded the price increase and a few months later broke with the IMF.

What can be done to put an end to such tragic distortions of economic policy-making?

A report of this has now been published by United Nations University Food and Nutrition Bulletin. vol 9 no 1, March, 1987. 
In this brief note, I would like to forego more general political and economic analysis of the underlying forces pressing on these countries and instead concentrate on some areas of international and national action in which change seems possible but is held back for three reasons too often neglected in academic analysis:

- lack of leadership

- failure to develop an implementation strategy

- the lack of specific knowledge of alternatives and of relevant research.

In anticipation of sighs of intellectual boredom and disbelief from some of those more used to weightier analyses, let me set forth clearly the two convictions underlying the analysis which follows. First, that in spite of obvious conflicts of interest between creditor and debtor countries, and between those making most of the economic and political decisions and those suffering the consequences, all of these parties now recognise that there is some space for improving the outcome in terms of human welfare. Indeed there is more room for manoeuvre than may often be realised, which concerned governments and international agencies could use constructively, if they chose. Second, that the creative use of this space will depend as much on bureaucratic leadership and followthrough, as it will on political decision-taking.

Perhaps this long-winded explanation is what Keynes eloquently summarised, but which is still too often ignored: 'the power of vested interests is vastly exaggerated compared with the gradual encroachment of ideas'.

\section{Toward a Functioning Implementation Strategy}

One needs to work in an international bureaucracy to appreciate fully the complications of communications, management, motivation and, simply, getting things done. Implementation strategy is perhaps no more than a careful analysis of a host of the bureaucratic specifics and of the tactical requirements of forming a strategy for ensuring that what is agreed to be policy is carried through into action in a way which will end up implementing the policy with a fair degree of effectiveness and cost-efficiency. But however obvious and basic, it is clear from my limited experience that most international agencies are very far from developing such implementation strategies in this vital area of action.

Let me make clear the issue with an example. I was asked in UNICEF's Executive Board to report on our implementation strategy for carrying out UNICEF's new strategy for supporting women in development. I duly reported on our programme objectives, our policy directive to the field, and on the beginnings of programme implementation in a number of countries. But this, I discovered, was not what was wanted. In contrast, a coherent strategy for implementation was wanted which not only set out the objectives and devised a policy directive - but which analysed how we would ensure the objectives and directives were understood by all who had responsibility for implementing programmes or other actions related to them; that those responsible for implementation had the training and the motivation to ensure effective implementation; that supervisors would ensure that the directive would be carried into action and that implementation and results were properly monitored and reported upon.

The Canadian government reported their own experience, to the effect that the implementation strategy on policy for women's support had been developed in a participatory process in which all concerned, office by office, section by section, discussed and proposed how effective implementation of the goals could best be achieved. These proposals were analysed, reviewed and consolidated into an agency-wide implementation strategy. This is a sign of a bureaucracy being serious about implementation.

I believe that implementation strategies are now seriously needed by a number of international agencies and governments, if the acknowledged importance of incorporating concern for vulnerable groups is to be adequately incorporated into the making and carrying out of adjustment policy. This is all the more important because, by convention, adjustment policy is still primarily treated as a strict matter of economic-financial policy-making, almost always restricted to the Ministry of Finance and the Central Bank. Those with professional expertise and the experience required to design and implement programmes reaching out to small farmers, women, the poor or dealing with problems of health, education or nutrition are elsewhere in government, nongovernment organisations or in political and community organisations.

An implementation strategy should cover several elements:

- a clear statement of objectives, related to all the areas of action of the agency concerned;

- a set of clearly defined policies and activities capable of accomplishing these objectives and/or specific and well analysed examples of alternatives which can be used as models, to be disseminated beyond the sphere of those immediately responsible for their enactment;

- a plan for ensuring that those responsible for implementation at the different levels of the organisation are alerted to these responsibilities and provided with the briefing, orientation and where necessary the training to give them the motivation and capacity to ensure policy is carried out;

- plans and procedures for monitoring imple- 
mentation by staff concerned, including mechanisms for support and procedures for course correction;

- a mechanism for monitoring changes in the human situation, as a criterion of success and as a guide to course correction when current strategies are not proving adequate;

- since a number of parties are involved whose support is required or will be helpful - different ministries of government, donor agencies, various concerned UN agencies, as well as the World Bank and the IMF - some form of understanding and collaborative mechanism is also needed to enable the efforts of these various parties to be aligned in support of the adjustment process as effectively as possible. In principle, the Consultative Groups and Roundtable processes, led respectively by the World Bank and UNDP, serve this purpose. But at least some changes will be needed in the way they operate at present, if the broader range of human concerns is to be adequately addressed and if those parties not yet part of the process are to be brought in.

\section{International Experimentation}

The approach advocated above is not yet part of the current approach to adjustment policy, either in formulation, mobilisation of international support, implementation or monitoring. For this reason, there is more than the normal need for creative experimentation in trying both new approaches and new mechanisms. Indeed, given the weak performance of most adjustment programmes, even when measured by the conventional criteria of growth, inflation reduction and restoration of the balance of payments, it is remarkable how limited in number and scope have been the conscious efforts to experiment with alternatives or systematically to monitor and analyse those alternatives which have been tried.

Even more is this true when assessing adjustment policy in terms of broader criteria. Here the weaknesses of the past are even more readily acknowledged, yet the limited range of experimentation and the lack of systematic analysis of those alternatives which have been tried is still more striking.

Fortunately, some of these deficiencies have now been recognised. Both $M$. de Larosière and $M$. Camdessus have encouraged more active exploration of alternatives and pledged the willingness of IMF missions '- when preparing stand-by agreements, and when requested by a member country - to consider with the authorities the implications of alternative approaches to adjustment for the distribution of income, with a view in particular to sheltering the poorest' [IMF statement to ECOSOC, July, 1986].

Eight months after this offer to consider alternatives was first made, the IMF reported [to the $\mathrm{ACC} / \mathrm{SCN}$ in March 1987] that no country to date had taken the IMF up on its offer to consider alternatives. While there could be several explanations of this, in my view it shows the need for institutionalising the consideration of alternatives, as a routine part of adjustment policy-making and the need for defining what specific measures are possible and the extent to which different measures will protect vulnerable groups. Visiting missions could be specifically required to explore alternatives with the government concerned and to indicate in their reports the main options considered. More important, the Fund, the Bank and some of the other main institutions involved could be asked to report on alternative approaches being tried, and to assess their special characteristics and their strengths and weaknesses in the different contexts in which they were being operated.

Alternatives could also usefully be explored with respect to institutional mechanisms for mobilising support and collaboration. At the moment, the consultative group or roundtable is the centre of the formal process, being the culmination of many months of preparation and setting the stage for a year or more of international support and of following through on pledges made. The consultative groups are probably more effective and more sensitively run than some outside critics suggest. Even so it is not difficult to hear complaints from countries or donors or different international agencies. In regard to broadening approaches to adjustment, the consultative groups and roundtables could play an important part: - by ensuring that the agenda and documentation for the consultative groups and roundtables routinely include material on changes in the national or regional situation with respect to nutrition, poverty, inequality, women and environment;

- by finding ways to bring in the professional interest and expertise of particular UN agencies and donors, while guarding against swamping the meeting with many new members and irrelevant or token representation. One way to achieve this might be to organise in-country preparatory meetings, focused specifically on the human needs and dimensions of the adjustment process. The analysis and conclusions of such meetings could later be reported to the main consultative group or roundtable meetings and proposals requiring financial support could be incorporated within the proposals and pledges of the main meeting;

- the Regional Development Banks and other regional institutions could have a special part to play in all this, especially by encouraging a regional sensitivity in the approaches and by ensuring that proper weight is given to regional initiatives and institutions in the whole adjustment effort. Regional perspectives may also help to avoid a 
simple polarisation between national demands and international requirements and perspectives and, by contributing a genuinely regional viewpoint, add positively and substantively to the outcome.

\section{TCDC and the Need for More Relevant \\ Research}

The value of exchanging experience on any of these alternatives follows directly from the paucity of information at present available. TCDC therefore has an exceptionally important part to play, both to disseminate information on different experiences of adjustment and on the process of decision-making and implementation, politically and administratively.

The value of specific and well analysed examples of adjustment alternatives tried - and of the actual results - can easily be underestimated. Such examples are often the most powerful force for persuading policy-makers that alternatives are possible, as well as being powerful stimuli for thinking positively about the specifics of what can be done. Examples are especially important with respect to the human face of adjustment policy in such areas as:

- the broad strategies followed by different countries, such as Zimbabwe, Indonesia, Peru;

- specific low-cost initiatives taken in the main social sectors of health, education, water and sanitation, housing, etc.;

- new forms of community or government organisation, tried or developed in the context of adjustment programmes;

- new international mechanisms of support;

If these are fruitful areas for exchange of experience, it follows they are also useful areas for analysis and research. Again, it is important to stress the need for including specifics and detail, not just broad perspectives and principle. Implementation involves detail, and it is often the lack of such detail which delays or hinders the practical development of policies, even when agreed politically. Even more unfortunate are the cases where lack of specifics and detail leads to inadequacies in design or implementation, which ends up in discrediting a whole line of action.

But it would be wrong to put the emphasis totally on pragmatic experience and practical detail. The links with theory (and ideology) are also vital, if only to counter the arguments which suggest that it is theoretically inappropriate or inefficient to take account of human needs in devising or implementing adjustment policy. Good theory is needed, if only to show up, and hopefully to drive out, bad theory.

\section{Annex}

International Statements on Growth Oriented Adjustment and the Protection of the Vulnerable
Over the last two years, awareness has grown, both of the human costs of economic difficulty in the developing countries and of the need for remedial action to protect the poor and vulnerable.

Nutrition objectives for the poor (should) form an explicit part of adjustment policies and programmes of governments and member organisations, including special compensatory measures where appropriate, with a view to providing an adequate level of nutrition for vulnerable groups.'

\section{The United Nations ACC Subcommittee on Nutrition April, 1986}

'Programmes of adjustment cannot be effective unless they command the support of governments and of public opinion. Yet this support will be progressively harder to maintain the longer adjustment continues without some pay-off in terms of growth and while human conditions are deteriorating. Likewise, it is hard to visualise how a viable external position can be achieved if large segments of the work force lack the vocational skills - or even worse, the basic nutritional and health standards - to produce goods that are competitive in world markets. Human capital is after all the most important factor of production in developing and industrial countries alike.'

'But the fact that adjustment need not conflict with growth and protection of basic human needs does not mean either that the latter automatically result from the former. No. The extent to which adjustment is compatible with growth and with an improvement in living standards depends in large part on what form that adjustment takes. Adjustment that takes the form of increases in exports, savings, investments and economic efficiency will clearly be more supportive of growth than that which relies on cuts in investment and in imports. Similarly, adjustment that pays attention to the health, nutritional and educational requirements of the most vulnerable groups is going to protect the human condition better than adjustment that ignores them.

This means, in turn, that the authorities will have to be concerned not only with if they close the fiscal deficit but also with how they do so.

The forms of adjustment that are most conducive to growth and to protection of human needs will not emerge by accident. They have to be encouraged by an appropriate set of incentives and policies. They will also require political courage.'

\section{M. de Larosière, Managing \\ Director of the IMF in his address to ECOSOC, July 4, 1986}

'The World Health Assembly calls on Member States to ensure, in cooperation with international 
financing institutions, that the health and nutritional status of the most disadvantaged social groups are protected when economic adjustment policies are designed and implemented.'

Thirty-Ninth World Health

Assembly Resolution 16 May, 1986

'The link between growth and a form of structural adjustment supportive of the most vulnerable groups in developing countries can be further strengthened by the complementary roles different international institutions play in assisting national governments. IFAD has directed its efforts towards a structural change in the rural poor's production capacity and productivity in its developing Member Countries, for both equity and growth purposes. This will complement other international institutions' efforts to promote growth while implementing social and other reforms geared towards the promotion of human resources.'

Idriss Jazairy, President IFAD

at second regular session of

ACC on Development and

International Economic

Cooperation, 1987

'Debt servicing cannot be met at the price of the asphyxiation of a country's economy, and no government can formally demand of its people privations incompatible with human dignity.

... the Church draws the attention of multilateral financial organisations and those who work in them to a few points for consideration:

- to examine the loan 'conditions' set by the

IMF openly in a way which is adapted to each developing country; to integrate the human factor in the 'increased surveillance' over the implementation of adjustment measures and the results achieved;

- to pay close attention to the selection and training of all those who work in multilateral organisations and who take part in situation analysis, and in decisions relative there to, and their subsequent implementation. Collectively and individually, these people bear a great responsibility. There is always the danger of remaining on the level of theoretical, technical or bureaucratic solutions, while at stake are human lives, the development of peoples, and solidarity among nations. Economic expert ise is indispensable, as is sensitivity to other cultures and direct and concrete experience with people and their needs. To give a firm base to these human qualities, a keen sense of the need to promote solidarity and international justice is also important.'

His Holiness Pope John Paul II Message for the Celebration of the World Day of Peace, December 27, 1986

'But the process of adjustment can impose heavy social costs on fragile societies. Tangible results and perceptible speed are necessary to avoid economic stagnation and political unheaval. I believe all of us now are more cognizant of the need to protect the poor during the adjustment period, and the World Bank's programmes increasingly take this into account.'
Barber B. Conable, Jr.,
President of World Bank, at UNCTAD VII, Geneva, July 10,1987

\begin{abstract}
'Too often in recent years, it is the poorest segments of the population that have carried the heaviest burden of economic adjustment. Hence, has emerged the notion of an IMF which is insensitive or which ignores the social aspects of economic policies. Here, too, the reality is different. Within its mandate and its possibilities, the Fund has given steadily greater attention to such aspects in recent years. The institution has expanded its contacts with $\mathrm{UN}$ related agencies that are experts in social policies, in order to sharpen its appreciation of the issues. We will continue to do so. Furthermore, as my predecessor made very clear at this Assembly a year ago, Fund missions are willing - when preparing standby programmes, and when requested by a member country - to consider with the authorities the implications of alternative approaches to adjustment for the distribution of income, with a view in particular to sheltering the poorest.
\end{abstract}

I should like today to reaffirm that willingness and, in doing so to express two convictions. The first is that adjustment does not have to lower basic human standards. In this context, the efforts of fellow agencies of the UN family both to protect social programmes in the face of unavoidable budget cuts and to make such programmes more efficient - delivering better services at less cost exemplify the types of things that are essential. My second conviction is that the more adjustment efforts give proper weight to social realities especially the implications for the poorest - the more successful they are likely to be.

But allow me again to make the point that adjustment programmes are not Fund programmes, only Fund-supported programmes. Within an agreed overall framework the final choice in the specification of policies bearing on income distribution and resource allocation must rest with the country itself.'

\footnotetext{
M. M. Camdessus, Managing Director of IMF at ECOSOC, June, 1987
} 